\title{
Efficient Investment signals for Distributed Generation
}

\author{
Philip Vogel \\ Chair of Energy Economics \\ University of Duisburg-Essen \\ (Campus Essen) \\ Universitaetsstr. 11 \\ 45117 Essen, Germany \\ Philip.Vogel@uni-due.de
}

\section{(1) Overview}

Distributed generation units (DG) are desirable in an environmental view but also have an impact onto the costs of electricity grids at the distribution and transmission level (cf. Auer (2006); Hoff and Wenger (1996)). This impact can be interpreted as external effects which significantly influence the efficiency of the overall electricity system. For the reason of internalisation, all benefits and costs of DG have to be considered in investment planning in order to build DG sources at sites where they are economically efficient (Donkelaar (2004); El-Khattam and Salama (2004) Weber and Vogel (2005)). Unfortunately, this is not an easy task in an unbundled industry where distribution and generation of electricity are not planned by one institution (Brunekreeft and Ehlers (2005)). In this analysis all possible policy options and -combinations for giving investment incentives to Distributed generation are investigated with a special focus on the long run investment signals related to DG. Thereby the focus will be laid on environmental policies and deep- and shallow charges for the internalisation of grid effects, but also the interplay with potential grid-regulation policies is briefly addressed.

\section{(2) Methods}

Within this analysis a partial equilibrium model is developed which analysis the efficiency of different policy options. In a first step, a hypothetical benevolent planner is presumed as a reference and it will be shown which kind of policy optimizes the overall welfare. In a second step it will be analysed if grid operators have the right incentives within different policy fields, or if their incentives distort the efficiency of certain measures.

\section{(3) Results}

The results of the above analysis show that it is best to separate the treatment of grid related and environmental externalities and that only marginal cost pricing of these externalities is yielding a socially optimal distributed generation structure. Thereby, the former externalities should be treated by the DSOs and the latter should be considered by the government separately. It will be shown that Deep charges, which allow the DSOs to charge DG freely are associated with monopoly power and that no efficient investment signals can be given unless price discrimination is applied. In principle, there exists a dilemma when choosing between deep or shallow charges. In the former case, 
the charges for DG-induced grid costs are too high and the remuneration for benefits is too low. Due to information asymmetries, in the latter case, there exists no possibility to differentiate between sites where positive or negative grid effects are dominant and therefore efficiency is not feasible.

\section{(4) Conclusions}

The first conclusion is that environmental externalities should be internalized separately from grid issues and that the commonly known first best policies are preferable for application. Theoretically, the only policy which might yield a first best result regarding grid externalities is the application of price discriminating deep charges, which are associated with substantial distributional side effects. In economic terms distributional issues are less important than issues of allocative efficiency and therefore a modified application of deep charges seems desirable. Every alternative lump sum compensation or charging of the benefits and costs of DG, can not result in a socially optimal combination of DG and grid capacities. Due to path dependencies it is only legitimized to apply shallow charges in the very short run. Due to the fact, that grid operators are subject to increasingly tightening regulation targets, the spreading of DG units and the involved costs have to be considered within planned or existing grid regulation schemes.

\section{References}

Auer, H. (2006): "The Relevance of Unbundling for Large-scale RES-E Grid Integration in Europe", Energy and Environment 17(6).

Brunekreeft, G.; Ehlers, E. (2005): "Ownership unbundling of electricity distribution networks and distributed generation ", Competition and regulation in network industries 1(1): 63-86.

Donkelaar, M. T. (2004): "A survey of solutions and options for the integration of distributed generation into electricity supply systems", Energy and Environment 15(2): 323-332.

El-Khattam, W.; Salama, M. M. A. (2004): "Distributed generation technologies, definitions and benefits", Electric power systems research 71: 119-128.

Hoff, T. E.; Wenger, H. J.et al. (1996): "Distributed Generation, An Alternative to Electric Utility Investments in System Capacity", Energy Policy 24(2): 137-147.

Jamasb, T.; Neuhoff, K.et al. (2005): "Long-Term Framework for Electricity Distribution charges", CWPE 0551 EPRG 07, Retrieved 10.10.2006.

Weber, C.; Vogel, P. (2005): "Decentralized energy production and electricity market structures", Proceedings of the 4th Conference on Applied Infrastructure Research, Berlin. 